\title{
Past, present, and future : trends in sleep duration and implications for public health
}

\section{Matricciani, Lisa}

2017-10

Matricciani , L , Bin , Y S , Lallukka , T, Kronholm , E , Dumuid , D , Paquet , C \& Olds , T 2017 , ' Past, present, and future : trends in sleep duration and implications for public health ' , Sleep health , vol. 3 , no. 5 , pp. 317-323 . https://doi.org/10.1016/j.sleh.2017.07.006

http://hdl.handle.net/10138/299243

https://doi.org/10.1016/j.sleh.2017.07.006

publishedVersion

Downloaded from Helda, University of Helsinki institutional repository.

This is an electronic reprint of the original article.

This reprint may differ from the original in pagination and typographic detail.

Please cite the original version. 


\title{
Past, present, and future: trends in sleep duration and implications for public health ${ }^{\text {मे }}$
}

\author{
Lisa Matricciani, BPodHons, MNurs ${ }^{\mathrm{a}, \mathrm{g}, *}$, Yu Sun Bin, PhD ${ }^{\mathrm{c}, \mathrm{d}}$, Tea Lallukka, PhD ${ }^{\text {e,f }}$, Erkki Kronholm, PhD ${ }^{\mathrm{e}}$, \\ Dorothea Dumuid, BPhysio, Hons ${ }^{\mathrm{a}}$, Catherine Paquet, $\mathrm{PhD}^{\mathrm{b}}$, Tim Olds, $\mathrm{PhD}^{\mathrm{a}, \mathrm{g}}$
}

a Sansom Institute, Alliance for Research in Exercise, Nutrition and Activity (ARENA), University of South Australia, Adelaide, SA, Australia

b Sansom Institute, Centre for Population Health Research, University of South Australia, Adelaide, SA, Australia

c Sleep Group, Charles Perkins Centre, University of Sydney, Sydney, NSW, Australia

d Central Clinical School, Sydney Medical School, NSW, Australia

e Finnish Institute of Occupational Health, Helsinki, Finland

${ }^{\mathrm{f}}$ Department of Public Health, University of Helsinki, Finland

${ }^{g}$ Murdoch Children's Research Institute, Melbourne, Australia

\section{A R T I C L E I N F O}

\section{Article history:}

Received 3 May 2017

Received in revised form 10 July 2017

Accepted 12 July 2017

\section{Keywords:}

Sleep

Trends

Children

Adults

Health

\section{A B S T R A C T}

Sleep is important for the physical, social and mental well-being of both children and adults. Over the years, there has been a general presumption that sleep will inevitably decline with the increase in technology and a busy 24-hour modern lifestyle. This narrative review discusses the empirical evidence for secular trends in sleep duration and the implications of these trends.

(C) 2017 National Sleep Foundation. Published by Elsevier Inc. All rights reserved.

\section{Introduction}

Sleep is important for the physical, social and mental well-being of both children and adults. Sleep duration, in particular, has received growing attention over the years and has been shown to have an important influence on many biological processes such as inflammation, glucose regulation, appetite and energy expenditure, ${ }^{1-4}$ as well as psychological processes such as memory consolidation and attention. ${ }^{5-9}$ Collectively, these findings are thought to explain associations found between short sleep duration and adverse outcomes, such as obesity, diabetes, cardiovascular disease, and depression, as well as decreased work productivity and road accidents. $3,10,11$

\footnotetext{
岤 Funding/acknowledgements: Lisa Matricciani was supported by the Australian Government Research Training Program Scholarship. Dorothea Dumuid was supported by the Australian Government Research Training Program Scholarship. Tea Lallukka was supported by the Academy of Finland (grant numbers \#287488, \#294096). Yu Sun Bin was supported by a 2017 Career Development Award from the Sleep Research Society Foundation.

* Corresponding author at: School of Health Sciences, University of South Australia, City East, Adelaide, SA 5000.

E-mail address: matla005@mymail.unisa.edu.au (L. Matricciani).
}

Given the importance of sleep duration to health, concerns have been raised that insufficient sleep is pervasive and inevitable in today's 24-hour society. ${ }^{12,13}$ Continual advances in technologies such as artificial lighting, television, personal computers, the internet, smartphones and other screen-based devices are all believed to contribute to shorter sleep. ${ }^{12}$ This seemingly inevitable decline in sleep has raised health and economic concerns. Specifically, sleep duration may be an important modifiable lifestyle behavior affecting population health, well-being, and quality of life and therefore an important contributor to health and economic costs.

Although it is widely presumed that sleep is declining as society 'modernizes', the empirical evidence for sleep trends has received limited attention and discussion. ${ }^{12,13}$ Secular trends in both children's and adults' sleep provide important epidemiological insights into better understanding the contribution of sleep to population health. Such trends play an integral role in informing public policies, interventions and preventive measures, as well as prompting calls for action. ${ }^{14}$ Given that historical trends in sleep duration often form the impetus for urgent interventions and policies, $3,15,16$ it is imperative to examine the strength of the evidence behind such recommendations in order to better inform public health strategies. 
The primary aim of this study is, therefore, to provide a narrative review of the evidence for secular trends in sleep duration in order to better understand the implications of current knowledge. This paper will focus on the sleep duration of school-aged children and adults. Although we acknowledge unique social and biological issues exist within sub-groups of the population examined (ie, young children, adolescents, early adulthood, working age and elderly) we examine trends broadly for children and adults. Infants and toddlers are omitted, as the nature of their sleep is qualitatively different from those of older age groups and thus the public health strategies for these groups will also be qualitatively different.

\section{Children's sleep}

\section{Children's sleep duration and health}

Shorter sleep durations have been shown to adversely affect children's physical health, cognitive ability and mood. ${ }^{17-19}$

Short sleep has been associated with increased weight status ${ }^{20-23}$ and has been suggested a possible contributor to children's obesity. Meta-analyses ${ }^{10,18}$ reporting an association between children's sleep duration and body mass index report statistically significant associations (OR 1.58-1.89). Short sleep is thought to increase the risk of obesity by increasing sympathetic activity, elevating cortisol and ghrelin levels, decreasing leptin levels and/or impairing glucose tolerance. ${ }^{24-26}$ In line with evidence that altered ghrelin and leptin levels affect hunger, ${ }^{27,28}$ experimental sleep studies show that children with extended sleep times consume fewer calories and weigh less than children with restricted sleep time. ${ }^{26,29}$ Although less extensively examined, ${ }^{30}$ short sleep has also been associated with impaired glucose metabolism and insulin resistance. While longitudinal studies also identify an association between short sleep in children and future weight gain, ${ }^{31-33}$ evidence that children's sleep duration leads to the development of future diabetes are limited and conflicting. ${ }^{34}$

Sleep duration has also been identified as important for cognitive function. Children with shorter sleep have been shown to display more behavioral problems, have poorer executive functioning and impaired school performance. ${ }^{17,19,35,36}$ These findings have been supported by a meta-analysis of 86 studies, ${ }^{37}$ however, most studies examined self-reported sleep and the overall effect sizes are small $(r<0.1)$. Experimental studies examining cognitive function in children consistently report poorer functioning in restricted sleep conditions compared to baseline (ie, usual sleep) or extended sleep. ${ }^{35,38-40}$

It is also important to note that adolescents are particularly susceptible to short sleep due to biological processes, which occur during puberty. ${ }^{41}$ Specifically, the secretion of melatonin, a hormone that helps regulate the sleep wake/cycle, is delayed during puberty, causing delayed sleep onset during adolescence. ${ }^{41}$ Given physiological changes, together with academic (eg, homework) and recreational activities (eg, part-time employment) that often compete with sleep time, declines in sleep are often observed during adolescence. ${ }^{42}$

Most studies on children report a linear relationship between sleep duration and health. ${ }^{17}$ This is in contrast to the U-shaped association seen in most adult populations (detailed below). Differences in the shape of the sleep-health relationship between children and adults have not been systematically investigated. It is possible that a U-shaped association between sleep duration and health also exists in children, but is difficult to detect as long sleep is practically restricted by other activities, such as schooling, in the 24-hour day.

Despite there being a growing body of evidence to support the link between sleep duration and health outcomes in children and adolescents, it is important to acknowledge that much of the epidemiological evidence is based on self-report data. Self-report measures of children's sleep, although correlated with objective measures, such as actigraphy and polysomnography, are subject to limitations associated with recall and reporter bias. ${ }^{43}$ Authors have also questioned whether statistically significant associations reported for children's sleep duration and measures of physical health, such as obesity, are clinically significance. ${ }^{44,45}$ Nevertheless, currently available studies provide evidence that detriments in health are associated with shortened sleep. Accordingly, if secular declines in children's sleep are occurring, it is a reasonable cause for concern.

\section{Trends in children's sleep duration}

Up until recently, it was widely presumed that children are sleeping less than they did in the past, despite limited and conflicting evidence to support this belief. ${ }^{13}$ As identified in our scholarly genealogy of the literature, which aimed to determine the evidence for claims of a secular trend in children's sleep, there were most claims of a decline, despite there being mixed available evidence. ${ }^{13}$ Specifically, our previous study identified 51 papers with claims of a secular trend in school-aged children's sleep duration, of which 34 papers cited evidence of a decline, while the remaining 17 studies provided primary evidence which showed that secular trends in children's sleep are mixed. ${ }^{13}$

Given the conflicting and limited evidence for secular trends in children's sleep, we have also conducted a meta-analysis of data from 690,747 children across 20 different countries to determine trends in children's sleep since $1901 .{ }^{46}$ The results of this study confirmed popular beliefs of a secular decline although the decline identified in this study was not as extreme as many of the claims that have been made. We found an overall decline of $0.76 \mathrm{~min} / \mathrm{y}$ over the last century. This is in contrast to suggestions of declines of 1 hour over the last 30 years and 40 years, ${ }^{47,48}$ indicating that children are experiencing a secular decline of 1.5 to $2.0 \mathrm{~min} / \mathrm{y}$, estimates more than double the $0.76 \mathrm{~min} / \mathrm{y}$ identified in our study. ${ }^{46}$ Significant differences were observed according to day-type, age and sex. Specifically, the median rate of change was greatest on non-schooldays ( $0.48 \mathrm{~min} / \mathrm{y}$ ) compared to schooldays $(0.38 \mathrm{~min} / \mathrm{y})$, for older children ( $0.86 \mathrm{~min} / \mathrm{y}$ for 16 - to 18 -year olds) compared to younger children ( $0.32 \mathrm{~min} / \mathrm{y}$ for 5 - to 8 -year olds), and for boys ( $0.89 \mathrm{~min} / \mathrm{y}$ ) compared to girls $(0.70 \mathrm{~min} / \mathrm{y}){ }^{46}$

Since the publication of our reviews, ${ }^{13,46}$ a further attempt has been made to understand trends in children's sleep. Keyes and colleagues $^{49}$ examined the frequency of self-reported sleep being greater than 7 hours in a representative sample of 272,077 US adolescents, aged 12 to 19 years, between 1991 and 2012. Consistent with our review, a decline was observed, with adolescents being $30 \%$ less likely to report seven or more hours of sleep in 2012 compared to 1991. However, it needs to be noted that actual sleep duration was not reported in the study, ${ }^{49}$ only sleep duration of 7 hours or more and sleeping less than needed.

\section{Adult's sleep}

\section{Adult's sleep duration and health}

Akin to studies on children, sleep duration has been associated with a wide range of health outcomes in adults. Scientific attention on adult sleep dates from the early 19th century, when experimental studies demonstrated the biological necessity of sleep ${ }^{50}$ and the acute detrimental effects of sleep deprivation on well-being. ${ }^{51-53}$ However, evidence suggesting there may be long-term health effects of habitual short sleep has only emerged in recent decades. ${ }^{54}$

In contrast to the literature on children, which predominantly focuses on the detrimental effects of shorter sleep durations, both long and short sleep durations appear to be detrimental to health in adults. In 1964, a U-shaped relationship between self-reported sleep duration and mortality was found in the American Cancer Society Cohort. ${ }^{54}$ The study of 10,082 men aged over 30 found the lowest mortality ratio in those with 7 hours of sleep, with deaths increasing 
on either side of this nadir. The same curve was seen for all age groups including and up to those aged 85 years and above. This finding resulted in the belief that 7 hours of sleep was the optimal amount of sleep for adults and that shorter or longer sleep durations were unhealthy.

Population studies continue to show a U-, and in some cases, a Jshaped association between sleep duration and health. ${ }^{55,56}$ Middling sleep durations of 7 to 8 hours are associated with the lowest risks of mortality and morbidity, while extremely short or long sleep durations are linked to increased health risks. Short sleep durations have been generally defined as 6 hours or less of sleep nightly and long sleep usually refers to durations of 9 hours or more. Prospective studies show both short and long sleep durations increase the risk of all-cause mortality, ${ }^{57}$ cardiovascular disease, ${ }^{11}$ diabetes, ${ }^{58}$ hypertension ${ }^{59,60}$ and more controversially, obesity. ${ }^{15}$

\section{Trends in adults' sleep duration}

The notion that adults are chronically sleep-deprived and are sleeping less than they used to is widespread, in both the popular and academic literature. ${ }^{61}$ Media headlines highlight the degree of sleep loss revealed by popular polls, while perusal of the scientific literature show the phrase "an increasingly sleep-deprived society" occurs in publications across disciplines. Targeted searches for phrases such as "no change in sleep duration" or "increasing sleep" revealed no instances of manuscripts that contend an increase in sleep duration or alternatively that sleep was unchanged.

Despite these claims, systematic investigations reveal that there is little evidence to support the assertion that adult sleep duration has decreased in recent decades. Our systematic review of the literature identified 12 studies with information on sleep duration trends in 15 countries: sleep duration had declined in six countries, but increased in seven other countries, with mixed results found for two. ${ }^{62}$ That is, for every country where sleep duration was shown to be in decline, there was another in which sleep was increasing, with no clear social or economic grouping of the countries that might explain the diverse trends. ${ }^{62}$

To gain a better understanding of trends in adult sleep duration, we analyzed nationally representative survey data from 10 developed countries which were repeated between the 1960s to the 2000s. We found that instead of the anticipated increase in short sleep, long sleep durations had become more common across these nations. ${ }^{63}$ Short sleep had increased only in Italy and Norway but had decreased in Sweden, the United Kingdom, and the United States. Long sleep had increased in Australia, Finland, Sweden, the United Kingdom, and the United States but had decreased in Canada and Italy. No changes were observed in Germany or the Netherlands. The limited increases in short sleep duration challenge the claim of increasingly sleep-deprived societies, especially as long sleep has become more widespread than short sleep, at least when reported in time-use diaries. Subsequent studies in Denmark ${ }^{64}$ and Norway ${ }^{65}$ have also found no declines in sleep duration, strongly supporting the contention that the worldwide decline in adult sleep duration is overstated.

A recent meta-analysis of polysomnographic data tends to support these findings. ${ }^{66}$ Synthesis of data from healthy volunteers in the literature has revealed that objective sleep time has not declined over the past 50 years. While volunteers for research studies are not representative of the adult population at large, the lack of a significant decline in their sleep duration is consistent with the hypothesis that sleep duration has changed little over recent decades and is evidence against the large declines of $>1$ hour that has been claimed by others. $^{66}$

Notably the majority of null findings on adult sleep duration trends derive from analyses of time-use diaries, a method that has been critiqued as capturing time-in-bed rather than sleep time.
However, this method is arguably more objective than asking individuals how long they usually sleep using a single question, since participants are blind to the focus on sleep and the diary structure applies an external constraint that activities conducted during a 24hour day does indeed total 24 hours. In contrast, those studies which have reported declines in sleep duration have generally asked about average or habitual sleep durations using a single question. Sleep durations attained from single sleep questions have shown declines over time but equally, it is these single-question responses to sleep duration that have been linked to health outcomes. Given that sleep durations attained from single-phrased sleep questions have also been related to sleep quality, it is possible that such measures of sleep duration also include a subjective component of sleep quality. ${ }^{67}$

Are declines in sleep quality responsible for the perceived decreases in sleep duration, even while objective diaries suggest the time-opportunity for sleep has not changed? Recent narrative review has shown that indicators of poor sleep quality such as insomnia symptoms, use of sleep medications, and ambulatory care visits involving complaints of sleep disturbances have increased in several countries since the 1990s. ${ }^{68}$ These findings suggest that there is declining sleep quality in the adult population. However, this may be due to perceptions of declining sleep quality, increased awareness of sleep medicine and a lower threshold for help-seeking for sleep problems, as well as actual reductions in sleep quality. That is, both self-reported sleep duration and sleep quality are subjective concepts, at least as currently measured in the majority of populationbased studies. Consequently, the reasons for observed declines may be related to perceptions rather than reality. Until we have objective measures of sleep at a population level, we cannot say with any certainty that adult sleep duration or quality has deteriorated over time.

\section{Causes of secular trends in sleep duration}

Notions of a secular decline in sleep have been attributed to activities keeping people awake, such as television, work/school commitments and use of technology, and factors enabling people to stay awake, for example lighting and caffeine. ${ }^{12}$ Although this appears to stand true for children, with evidence, ${ }^{69,70}$ other factors such as poor health and deteriorating sleep quality may explain feelings of inadequate sleep, despite unchanged or increased sleep times in adults.

Shortened sleep among children is thought to have occurred as a result of progressive delays in children's bedtimes, but unchanged wake times. For instance, Dollman and colleagues ${ }^{70}$ found that although the school-day bedtimes of 10- to 15-year-old Australian children were later in 2004 than they were in 1985, their corresponding wake-times had not changed. Consistent with these findings, later bedtimes have also been reported for children living in Switzerland, ${ }^{69}$ Finland, ${ }^{71,72}$ Norway, ${ }^{73}$ Germany ${ }^{74}$ and Iceland. ${ }^{75}$

Screen-based devices such as televisions, computers and mobile phones have been associated with delays in bedtimes. ${ }^{23,76}$ In a study by Van den Bulck, ${ }^{77}$ for example, it was found that television viewing, computer game playing, and internet use among children was associated with delayed bedtimes as well as less time in bed. Study commitments have also been recognized as reasons that children stay up late and experience shorter time spent sleeping. ${ }^{41,78}$ Yang and colleagues ${ }^{79}$ found that homework determined the bedtimes of 20.4 percent of Korean students in grades 5 to 12. In addition to school commitments, part-time employment among children is also on the rise, and may contribute to later bedtimes and shorter sleep times. Carskadon and colleagues, ${ }^{80}$ for example, noted that adolescents who worked more than 20 hours a week went to bed later and slept fewer hours each night than those children who did not work. 
Although there has been no consistent decline in adult sleep durations globally, there is no question that some sections of the adult population achieve shorter sleep durations and may be more sleep deprived than others. The main constraint on adult sleep time and therefore sleep duration appears to be employment: those who are employed sleep less than those unemployed, ${ }^{81}$ those with multiple jobs sleep less than those with only one role, ${ }^{81}$ those with long work hours, ${ }^{82}$ those whose jobs require lengthy commutes, ${ }^{83}$ and certain occupations such as managers, transport/warehouse workers, and those in manufacturing are at higher risk of short sleep. ${ }^{84}$ Unpaid work such as childcare and caring for older or disabled friends and family is also associated with reduced sleep durations. ${ }^{81}$ The effect of shift work on sleep duration is less clear, possibly due to the different types of shift work available. Pilcher and colleagues, ${ }^{85}$ for example, identified shorter sleep in permanent night shift workers, but longer sleep in permanent evening shift workers. Rotating shift work has also been shown to affect sleep duration, with different effects reported for the different types and speeds of rotating shift work. $^{85}$

The use of technology and its impact on adult sleep is less well explored than that of technology and children's sleep. One crosssectional study has reported that more time spent watching television is associated with shorter sleep times, ${ }^{86}$ although the possibility of reverse causality, that adults who require less sleep watch more television, cannot be ruled out. A prospective study in young adults aged 20 to 24 years has found that greater computer use predicts sleep disturbances on 1-year follow-up, which suggests that screenbased technologies may impact on sleep quality and therefore subjective sleep duration. ${ }^{87}$

Electricity allows individuals to stay awake longer. Although there is relatively little empirical evidence, the development of the light bulb in 1874 is widely accepted as the starting point for secular declines in children's sleep duration ${ }^{88}$ and has been described as 'Edison's anti-sleep revolution'. ${ }^{89}$ While there is some evidence to show that individuals without electrical lighting tend to sleep more than those with electrical lighting, ${ }^{90}$ there is also evidence to suggest that although time in bed may be longer, the difference in total sleep duration is small ${ }^{91}$ and in some cases sleep is (even) shorter. ${ }^{92}$

Caffeine has been described as another main reason that individuals are not getting enough sleep. ${ }^{48}$ Pollak and Bright, ${ }^{93}$ in a study of 191 American students aged 12 to 14 years, found that higher caffeine intake was associated with shorter nocturnal sleep duration. Similarly, Orberta and colleagues, ${ }^{94}$ in a cross-sectional study of 4243 adolescents, found that adolescents who consumed caffeine (either as coffee or soft drinks), were twice as likely to have sleep disturbances compared to adolescents who did not. Given the crosssectional nature of these studies, it is important to consider the possibility of reverse causality. It is also difficult to determine secular trends in caffeine consumption, as the evidence appears mixed. ${ }^{95-101}$

Social trends, involving increased technology use and shift work, are thought to not only affect sleep time, but also impair sleep quality and increase day-to-day sleep time variability. Circadian disruption in the form of night shift work alternating with days off work will contribute to poor sleep quality. Likewise, poor sleep quality may result in underestimates of subjective sleep time reports. ${ }^{102,103}$ Feelings of inadequate or poor sleep may also prompt an increase in sleep medication use, possibly increasing total sleep time, but not necessarily feelings of 'adequate' sleep. In the United States, there has been an exponential increase in sleep medication prescription over recent years, coinciding with self-reported declines in sleep quality and quantity. ${ }^{104}$ Collectively, these factors may help to explain the observed trends in adult sleep over time.

It is also possible that adults' sleep time or perception of insufficient sleep has increased in response to an increase in sleep need. For example, an increase in cognitive tasks over the last century, such more time spent in education, a rise in standardized intelligence scores and an increase in the number of cognitively demanding jobs, ${ }^{105,106}$ may have increased adult sleep requirements. Given the importance of sleep for learning and memory, ${ }^{107}$ feelings of insufficient or poor sleep may reflect the need for more sleep in order to cope with the increased cognitive demands of modern life.

\section{Implications of trends in sleep duration}

An understanding of secular trends in sleep is important for public health policies and intervention to promote sleep and reduce the adverse consequences associated with shorter and longer sleep durations. The small but consistent declines observed in children's sleep are concerning given that shorter sleep durations have been associated with negative health outcomes. Despite these concerns, declines in sleep do not necessarily indicate that children are not getting 'enough' sleep. Indeed, declines in sleep may suggest that ${ }^{1}$ children are currently not sleeping enough, ${ }^{2}$ children used to sleep more than they needed, or $^{3}$ there is not a specific amount of sleep that children need.

In contrast, the work on adult sleep duration suggests that the time opportunity for sleep has not been encroached on by social trends. However, the perception of declining sleep duration is important to address as subjective sleep duration remains predictive of adverse health outcomes. ${ }^{11,17,18}$ There may be issues of unmeasured confounding in studies linking self-reported sleep duration and health, and it would be important to identify what those confounding factors are in order to understand whether sleep duration is causally linked to long-term health and therefore a worthy target of public health intervention. Currently, it appears that short and long sleep durations in adults also capture some aspects of sleep quality and there appear to be declines in this facet of sleep as measured by healthcare seeking and medication use. ${ }^{68}$ It is unclear if these indicate an increased awareness of sleep and, therefore, a lower threshold for help-seeking for sleep problems, or actual reductions in sleep quality, and, therefore, the perception of increasingly inadequate sleep.

Optimal sleep is complex and poorly understood. Definitions of optimal sleep vary from the amount recommended by authorizing bodies to "the daily amount of sleep that allows a subject to be fully awake (ie, not sleepy) and able to sustain normal levels of performance during the daytime" 108 as well as "the amount of sleep required to feel refreshed in the morning". ${ }^{109}$ However, such definitions have been contested, with arguments that there is "no magic number" for optimal sleep. ${ }^{110-112}$

Despite uncertainties surrounding definitions of optimal sleep, sleep duration has traditionally been used as a marker of adequate sleep, with the presence of sleep duration recommendations reinforcing this notion. ${ }^{12,113,114}$ Sleep recommendations do, however, acknowledge the complexity of optimal sleep and that sleep need may be influenced by inter- and intra-individual factors. ${ }^{113}$ For example, health authorities recognize that everyone may have different sleep requirements and that other characteristics of sleep, such as sleep quality, timing, composition, day-to-day variability, and continuity also play an important role. ${ }^{115,116}$ Likewise, it is also recognized that behavioral adaptations and environmental contexts may also alter sleep requirements. ${ }^{115,116}$ Although efforts have been made to inform current sleep recommendations, much more work is needed in this area, particularly in order to appropriately inform public policies. ${ }^{113}$

\section{Public health implications of secular trends in sleep duration}

Given that the current literature suggests detriments in health are associated with shorter sleep durations in children and both long and short sleep durations in adults, current trends in sleep are concerning 
and support the need for continual monitoring and intervention to ensure optimal sleep.

Public health interventions for sleep are currently in their infancy, with the majority raising public awareness of sleep health. For example, the American Academy of Sleep Medicine, the Centers for Disease Control and Prevention, and the Sleep Research Society partnered on the Healthy Sleep Project, in an effort to improve public health by promoting healthy sleep. ${ }^{117}$ The initiative included the Sleep Well, Be Well campaign, which highlighted the importance of adequate and consistent sleep, avoiding alcohol and caffeine before bed and seeking medical advice for sleep problems. Consistent with these messages, public health bodies are also increasingly acknowledging that sleep is equally important as diet and physical activity, which have received more public attention. For example, Heffron ${ }^{117}$ reminds us that "sleep is one of the three pillars (diet, exercise and sleep) of a healthy lifestyle", while the Perry and colleagues ${ }^{118}$ suggests that "sleep should be viewed as being as critical to health as diet and physical activity". In spite of these efforts, the impact of these strategies remains unclear and highlights a need to better monitor population sleep.

Monitoring sleep as part of population health surveillance programs may be considered a vital first step towards public health promotion and prevention strategies. For instance, the US Behavioral Risk Factors Surveillance System began asking about insufficient sleep in 1995, and added an optional module in 2009, which also asked about sleep duration, daytime sleepiness and snoring. ${ }^{119}$ There is a general need to implement sleep monitoring in public health surveillance systems worldwide as well as a specific need to improve and standardize the measurement of sleep duration and other sleep characteristics in these systems.

Population-based sleep duration has traditionally relied on selfreport data. Many countries, for example, have time-use surveys, and while it is possible to derive sleep duration and sleep timing from these surveys, these methods also require standardization so that the results can be compared across countries and across time. Further, while self-report methods may have face validity, there is currently no validated measure of self-reported sleep duration. It is known that asking about sleep duration in different ways changes the estimate depending on how question is framed. ${ }^{43}$ The precision of sleep measurements also need to be considered, for example, rounding sleep to within 5,15 or even 60 minutes, may lead to marked differences.

The disadvantages of examining self-reported sleep, and the need to examine objectively-measured sleep have been recognized. ${ }^{120,121}$ Objectively measured sleep, such as sleep measured via actigraphy, is able to assess both children's and adults' sleep in an ecologically valid setting, over multiple nights and is not influenced by recall or reporter bias, unlike self-report measures. Representative, population-based studies that objectively measure sleep are not only possible, but feasible.

\section{Conclusion}

Sleep is undoubtedly important for health. In spite of this, children's sleep appears to be declining, with important differences according to age, sex and region, while the evidence for adults is mixed. Although it remains unclear as to what constitutes optimal sleep, investigating trends in sleep is important given evidence to suggest that short sleep in children and both short and long sleep in adults are associated with poorer health. There is a need for ongoing population-based surveillance of sleep to examine population sleep trends into the future. There is a need to move from traditional questionnaire-based measures of sleep duration towards objective measures of sleep which have the capacity to capture multiple aspects of sleep (duration, timing, quality, and variability), all of which may contribute to and influence optimal sleep. Lastly, there is a need to consider sleep part of the 24-hour activity spectrum and to investigate the combined impact of 24-hour behavior on health outcomes.

\section{Disclosure}

There are no disclosures to declare.

\section{References}

1. St-Onge M. The role of sleep duration in the regulation of energy balance: effects on energy intakes and expenditure. J Clin Sleep Med. 2013;9(1):73-80.

2. Morselli L, Leproult R, Balbo M, Spiegel K. Role of sleep duration in the regulation of glucose metabolism and appetite. Best Pract Res Clin Endocrinol Metab. 2010; 24(5):687-702.

3. Cappuccio F, Miller M, Lockley S. Sleep, Health, and Society: From Aetiology to Public Health. USA: Oxford University Press; 2010

4. Al Khatib H, Harding S, Darzi J, Pot G. The effects of partial sleep deprivation on energy balance: a systematic review and meta-analysis. Eur J Clin Nutr. 2016;2: $1-11$.

5. Backhaus J, Hoeckesfeld R, Born J, Hohagen F, Junghanns K. Immediate as well as delayed post learning sleep but not wakefulness enhances declarative memory consolidation in children. Neurobiol Learn Mem. 2008;89(1):76-80.

6. Kopasz M, Loessl B, Hornyak M, Riemann D, Nissen C, Piosczyk H, et al. Sleep and memory in healthy children and adolescents-a critical review. Sleep Med Rev. 2010;14(3):167-177.

7. Walker M, Stickgold R. Sleep, memory, and plasticity. Annu Rev Psychol. 2006; 57(1):139-166.

8. Wilhelm I, Diekelmann S, Born J. Sleep in children improves memory performance on declarative but not procedural tasks. Learn Mem. 2008;15(5):373-377.

9. Walker M. The role of sleep in cognition and emotion. Ann N Y Acad Sci. 2009; 1156(1):168-197.

10. Cappuccio F, Taggart F, Kandala N, Currie A, Piele E, Stranges S, et al. Metaanalysis of short sleep duration and obesity in children and adults. Sleep. 2008; 31(5):619-926.

11. Cappuccio FP, Cooper D, D'Elia L, Strazzullo P, Miller MA. Sleep duration predicts cardiovascular outcomes: a systematic review and meta-analysis of prospective studies. Eur Heart J. 2011;32(12):1484-1492.

12. Matricciani L, Olds T, Blunden S, Rigney G, Williams M. Never enough sleep: a brief history of sleep recommendations for children. Pediatrics. 2012;129(3): 548-556.

13. Matricciani L, Olds T, Williams M. A review of evidence for the claim that children are sleeping less than in the past. Sleep. 2011;34(5):651-659.

14. Chung K, Cheung M. Sleep-wake patterns and sleep disturbance among Hong Kong Chinese adolescents. Sleep. 2008;31(2):185-194.

15. McAllister EJ, Dhurandhar NV, Keith SW, Aronne LJ, Barger J, Baskin M, et al. Ten putative contributors to the obesity epidemic. Crit Rev Food Sci Nutr. 2009; 49(10):868-913.

16. Wells ME, Vaughn BV. Poor sleep challenging the health of a nation. Neurodiagn J. 2012;52(3):233-249.

17. Chaput JP, Gray CE, Poitras VJ, Carson V, Gruber R, Olds T, et al. Systematic review of the relationships between sleep duration and health indicators in school-aged children and youth. Appl Physiol Nutr Metab. 2016;41(6):S266-S282.

18. Chen X, Beydoun MA, Wang Y. Is sleep duration associated with childhood obesity? A systematic review and meta-analysis. Obesity. 2008;16(2):265-274.

19. Wolfson AR, Carskadon MA. Understanding adolescents' sleep patterns and school performance: a critical appraisal. Sleep Med Rev. 2003;7(6):491-506.

20. Chaput J, Lambert M, Gray-Donald K, McGrath J, Tremblay M, O'Loughlin J, et al. Short sleep duration is independently associated with overweight and obesity in Quebec children. Can J Public Health. 2011;102(5):369-374.

21. Hart CN, Cairns A, Jelalian E. Sleep and obesity in children and adolescents. Pediatr Clin North Am. 2011;58(3):715-733.

22. Bawazeer N, Al-Daghri N, Valsamakis G, Al-Rubeaan K, Sabico S, Huang T, et al. Sleep duration and quality associated with obesity among Arab children. Obesity. 2009;17(12):2251-2253.

23. Calamaro C, Park S, Mason T, Marcus C, Weaver T, Pack A, et al. Shortened sleep duration does not predict obesity in adolescents. J Sleep Res. 2010;19(4): 559-566.

24. Taheri S, Lin L, Austin D, Young T, Mignot E. Short sleep duration is associated with reduced leptin, elevated ghrelin, and increased body mass index. PLoS Med. 2004;1(3):e62.

25. Chaput J, Després J, Bouchard C, Tremblay A. Short sleep duration is associated with reduced leptin levels and increased adiposity: results from the Quebec family study. Obesity. 2007;15(1):253-261.

26. Hart C, Carskadon M, Considine R, Fava J. Changes in children's sleep duration on food intake, weight, and leptin. Pediatrics. 2013;132(6):e1473-e1480.

27. Cummings D, Frayo R, Marmonier C, Aubert R, Chapelot D. Plasma ghrelin levels and hunger scores in humans initiating meals voluntarily without time-and food-related cues. Am J Physiol Endocrinol Metab. 2004;287(2):297-304.

28. Wren A, Seal L, Cohen M, Brynes A, Frost G, Murphy K, et al. Ghrelin enhances appetite and increases food intake in humans. J Clin Endocrinol Metab. 2001;86(12):5992. 
29. Weiss A, Xu F, Storfer-Isser A, Thomas A, Ievers-Landis C, Redline S. The association of sleep duration with adolescents' fat and carbohydrate consumption. Sleep. 2010;33(9):1201-1209.

30. Matthews K, Pantesco E. Sleep characteristics and cardiovascular risk in children and adolescents: an enumerative review. Sleep Med. 2016;18(1):36-49.

31. Thind H, Davies S, Lewis T, Pekmezi D, Evans R, Baskin M. Does short sleep lead to obesity among children and adolescents? Current understanding and implications. Am J Lifestyle Med. 2015;9(6):428-437.

32. Magee L, Hale L. Longitudinal associations between sleep duration and subsequent weight gain: a systematic review. Sleep Med Rev. 2012;16(3):231-241.

33. Wu Y, Gong Q, Zou Z, Li H, Zhang X. Short sleep duration and obesity among children: a systematic review and meta-analysis of prospective studies. Obes Res Clin Pract. 2017; 11(2):140-150.

34. Dutil C, Chaput J. Inadequate sleep as a contributor to type 2 diabetes in children and adolescents. Nutr Diabetes. 2017;7(5):e266.

35. Fallone G, Acebo C, Seifer R, Carskadon M. Experimental restriction of sleep opportunity in children: effects on teacher ratings. Sleep. $2005 ; 28$ (1): 1561-1567.

36. Cooper P, Kohler M, Blunden S. Sleep and academic performance in indigenous Australian children from a remote community: an exploratory study. J Paediatr Child Health. 2012;48(2):122-127.

37. Astill RG, Van der Heijden KB, Van Ijzendoorn MH, Van Someren EJW. Sleep, cognition, and behavioral problems in school-age children: a century of research meta-analyzed. Psychol Bull. 2012;138(6):1109-1138.

38. Sadeh A, Gruber R, Raviv A. The effects of sleep restriction and extension on schoolage children: what a difference an hour makes. Child Dev. 2003;74(1):444-455.

39. Vriend J, Davidson F, Corkum P, Rusak B, Chambers C, McLaughlin E. Manipulating sleep duration alters emotional functioning and cognitive performance in children. J Pediatr Psychol. 2013;38(10):1058-1069.

40. Randazzo A, Muehlbach M, Schweitzer P, Walsh J. Cognitive function following acute sleep restriction in children ages 10-14. Sleep. 1998;21(1):861-868.

41. Carskadon M. Factors Influencing Sleep Patterns of Adolescents. In: Carskadon M, editor. Adolescent Sleep Patterns: Biological, Social, and Psychological Influences. Cambridge: Cambridge University Press; 2002. p. 4-27.

42. Olds T, Blunden S, Petkov J, Forchino F. The relationships between sex, age, geography and time in bed in adolescents: a meta-analysis of data from 23 countries. Sleep Med Rev. 2010;14(6):371-378.

43. Matricciani L. Subjective reports of children's sleep duration: does the question matter? A literature review. Sleep Med. 2013;14(4):303-311.

44. Horne J. Short sleep is a questionable risk factor for obesity and related disorders: statistical versus clinical significance. Biol Psychol. 2008;77(3):266-276.

45. Horne J. Obesity and short sleep: unlikely bedfellows? Obes Rev. 2011;12(5): e84-e94.

46. Matricciani L, Olds T, Petkov J. In search of lost sleep: secular trends in the sleep time of school-aged children and adolescents. Sleep Med Rev. 2012;16(3): 203-211.

47. Shinomiya H, Takeuchi H, Martoni M, Natale V, Harada T. Comparative study on circadian typology of Japanese and Italian students aged 12-18 years. Sleep Biol Rhythms. 2004;2(1):93-95.

48. Calamaro C, Mason T, Ratcliffe S. Adolescents living the 24/7 lifestyle: effects of caffeine and technology on sleep duration and daytime functioning. Pediatrics. 2009;123(6):1005-1010.

49. Keyes K, Maslowsky J, Hamilton A, Schulenberg J. The great sleep recession: changes in sleep duration among US adolescents 1991-2012. Pediatrics. 2015; 135(3):460-468

50. Patrick G, Gilbert J. Studies from the psychological laboratory of the University of Iowa. On the effects of sleep loss. Psychol Rev. 1896;1896(3):468-483.

51. Pilcher J, Huffcutt A. Effects of sleep deprivation on performance: a metaanalysis. Sleep. 1996;19(4):318-326.

52. Durmer J, Dinges D. Neurocognitive consequences of sleep deprivation. Semin Neurol. 2005;25(1):117-129.

53. McCoy J, Strecker R. The cognitive cost of sleep lost. Neurobiol Learn Mem. 2011; 96(4):564-582.

54. Hammond EC. Some preliminary findings on physical complaints from a prospective study of 1,064,004 men and women. Am J Public Health Nations Health. 1964;54:11-23.

55. Kurina LM, McClintock MK, Chen JH, Waite LJ, Thisted RA, Lauderdale DS. Sleep duration and all-cause mortality: a critical review of measurement and associations. Ann Epidemiol. 2013;23(6):361-370

56. Li W, Wang D, Cao S, Yin X, Gong Y, Gan Y, et al. Sleep duration and risk of stroke events and stroke mortality: a systematic review and meta-analysis of prospective cohort studies. Int J Cardiol. 2016;223:870-876.

57. Gallicchio L, Kalesan B. Sleep duration and mortality: a systematic review and meta-analysis. J Sleep Res. 2009;18(2):148-158.

58. Cappuccio FP, D'Elia L, Strazzullo P, Miller MA. Quantity and quality of sleep and incidence of type 2 diabetes: a systematic review and meta-analysis. Diabetes Care. 2010;33(2):414-420.

59. Guo X, Zheng L, Wang J, Zhang X, Li J, Sun Y. Epidemiological evidence for the link between sleep duration and high blood pressure: a systematic review and metaanalysis. Sleep Med. 2013;14(4):324-332.

60. Meng L, Zheng Y, Hui R. The relationship of sleep duration and insomnia to risk of hypertension incidence: a meta-analysis of prospective cohort studies. Hypertens Res. 2013;36(11):985-995.

61. Bin Y. Secular Trends in Sleep Duration and Implications for Public Health. Australia: University of Sydney; 2014.
62. Bin YS, Marshall NS, Glozier N. Secular trends in adult sleep duration: a systematic review. Sleep Med Rev. 2012;16(3):223-230.

63. Bin YS, Marshall NS, Glozier N. Sleeping at the limits: the changing prevalence of short and long sleep durations in 10 countries. Am J Epidemiol. 2013;177(8): 826-833.

64. Bonke J. Trends in short and long sleep in denmark from 1964 to 2009, and the associations with employment, SES (socioeconomic status) and BMI. Sleep Med. 2015;16(3):385-390.

65. Sivertsen B, Øverland S, Pallesen S. Trends in timing of sleep in the general population of Norway: 1980 to 2000. Percept Mot Skills. 2011;113(2):509-518.

66. Youngstedt S, Goff E, Reynolds A, Kripke D, Irwin M, Bootzin R, et al. Has adult sleep duration declined over the last 50+ years? Sleep Med Rev. 2016;28(1):69-85.

67. Bin Y. Is sleep quality more important than sleep duration for public health? Sleep. 2016;39(3):1629-1630.

68. Hoyos C, Glozier N, Marshall N. Recent evidence on worldwide trends on sleep duration. Curr Sleep Med Rep. 2015;1(4):195-204.

69. Iglowstein I, Jenni OG, Molinari L, Largo RH. Sleep duration from infancy to adolescence: reference values and generational trends. Pediatrics. 2003;111(2): 302-307.

70. Dollman J, Ridley K, Olds T, Lowe E. Trends in the duration of school-day sleep among 10- to 15-year-old south Australians between 1985 and 2004. Acta Paediatr. 2007;96(7):1011-1014

71. Pääkkönen H. What do schoolchildren in Finland do with their time? Loisir et Société. 2005;28(2):425-429.

72. Nuutinen T, Ray C, Roos E. Do computer use, TV viewing, and the presence of the media in the bedroom predict school-aged children's sleep habits in a longitudinal study? BMC Public Health. 2013;13(1):684

73. Vaage O. Adolescent time use trends in Norway. Loisir et Société. 2005;28(2): 443-460.

74. Randler C. Sleep length in German children and adolescents. SomnologieSchlafforschung und Schlafmedizin. 2009;13(2):89-91.

75. Thorleifsdottir B, Björnsson JK, Benediktsdottir B, Gislason T, Kristbjarnarson H. Sleep and sleep habits from childhood to young adulthood over a 10-year period. J Psychosom Res. 2002;53(1):529-537.

76. Honda M, Genba M, Kawakami J, Nishizono-Maher A. A sleep and life-style survey of Japanese high school boys: factors associated with frequent exposure to bright nocturnal light. Sleep Biol Rhythms. 2008;6(2):110-119.

77. Van den Bulck J. Television viewing, computer game playing, and internet use and self-reported time to bed and time out of bed in secondary-school children. Sleep. 2004;27(1):101-104.

78. Oka Y, Suzuki S, Inoue T. Bedtime activities, sleep environment, and sleep/wake patterns of Japanese elementary school children. Behav Sleep Med. 2008;6(1): 220-233.

79. Yang C, Kim J, Patel S, Lee J. Age-related changes in sleep/wake patterns among Korean teenagers. Pediatrics. 2005;115(1):250-256.

80. Carskadon M. Patterns of sleepiness in adolescents. Paediatrician. 1990;17(1): 5-12.

81. Bin Y, Marshall N, Glozier N. Secular changes in sleep duration among Australian adults, 1992-2006. Med J Aust. 2011;195(11-12):670-672.

82. Chatzitheochari S, Arber S. Lack of sleep, work and the long hours culture: evidence from the UK time use survey. Work Employ Soc. 2009;23(1):30-48.

83. Walsleben J, Norman R, Novak R, O'Malley E, Rapoport D, Strohl K. Sleep habits of Long Island rail road commuters. Sleep. 1999;22(6):728-734.

84. Luckhaupt S, Tak S, Calvert G. The prevalence of short sleep duration by industry and occupation in the National Health Interview Survey. Sleep. 2010:33(2):149-159.

85. Pilcher J, Lambert B, Huffcutt A. Differential effects of permanent and rotating shifts on self-report sleep length: a meta-analytic review. Sleep. 2000;23(2):1-9.

86. Basner M, Fomberstein K, Razavi F, Banks S, William J, Rosa R, et al. American time use survey: sleep time and its relationship to waking activities. Sleep. 2007;30(9):1085-1095.

87. Thomee S, Harenstam A, Hagberg M. Computer use and stress, sleep disturbances, and symptoms of depression among young adults-a prospective cohort study. BMC Psychiatry. 2012;12(1):176

88. Gangwisch J, Malaspina D, Boden-Albala B, Heymsfield S. Inadequate sleep as a risk factor for obesity: analyses of the NHANES I. Sleep. 2005;28(12):89-96

89. Cizza G, Skarulis M, Mignot E. A link between short sleep and obesity: building the evidence for causation. Sleep. 2005;28(10):1217-1220.

90. Peixoto C, da Silva A, Carskadon M, Louzada F. Adolescents living in homes without electric lighting have earlier sleep times. Behav Sleep Med. 2009; 7(2):73-80.

91. Knutson K. Sleep duration, quality, and timing and their associations with age in a community without electricity in Haiti. Am J Hum Biol. 2014;26(1):80-86

92. Samson D, Manus M, Krystal A, Fakir E, Yu J, Nunn C. Segmented sleep in a nonelectric, small-scale agricultural society in Madagascar. Am J Hum Biol. 2017.

93. Pollak C, Bright D. Caffeine consumption and weekly sleep patterns in us seventh-, eighth-, and ninth-graders. Pediatrics. 2003;111(1):42-46.

94. Orbeta R, Overpeck M, Ramcharran D, Kogan M, Ledsky R. High caffeine intake in adolescents: associations with difficulty sleeping and feeling tired in the morning. J Adolesc Health. 2006;38(4):451-453.

95. Harnack L, Stang J, Story M. Soft drink consumption among US children and adolescents: nutritional consequences. J Am Diet Assoc. 1999;99(4):436-441.

96. French S, Lin B, Guthrie J. National trends in soft drink consumption among children and adolescents age 6 to 17 years: prevalence, amounts, and sources, 1977/ 1978 to 1994/1998. J Am Diet Assoc. 2003;103(10):1326-1331. 
97. Smiciklas-Wright H, Mitchell D, Mickle S, Goldman J, Cook A. Foods commonly eaten in the United States, 1989-91 and 1994-96: are portion sizes changing. $J$ Am Diet Assoc. 2003;103(1):41-47.

98. Cordes H. Generation wired: caffeine is the new drug of choice for kids 1998. Available from http://www.metroactive.com/papers/sonoma/08.20.98/caffeine9833.html.

99. Tran N, Barraj L, Bi X, Jack M. Trends and patterns of caffeine consumption among US teenagers and young adults, NHANES 2003-2012. Food Chem Toxicol. 2016;94: 227-242.

100. Ahluwalia N, Herrick K. Caffeine intake from food and beverage sources and trends among children and adolescents in the United States: review of national quantitative studies from 1999 to 2011. Adv Nutr. 2015;6(1):102-111.

101. Drewnowski A, Rehm C. Sources of caffeine in diets of US children and adults: trends by beverage type and purchase location. Forum Nutr. 2016;8(3):154.

102. Xiang Y, Ma X, Lu J, Cai Z, Li S, Xiang Y, et al. Relationships of sleep duration with sleep disturbances, basic socio-demographic factors, and BMI in Chinese people. Sleep Med. 2009;10(10):1085-1089.

103. Park S, Cho M, Chang S, Bae J, Jeon H, Cho S, et al. Relationships of sleep duration with sociodemographic and health-related factors, psychiatric disorders and sleep disturbances in a community sample of Korean adults. J Sleep Res. 2010; 19(4):567-577.

104. Moloney ME, Konrad TR, Zimmer CR. The medicalization of sleeplessness: a public health concern. Am J Public Health. 2011;101(8):1429-1433.

105. Flynn J. The Flynn effect and Flynn's paradox. Dermatol Int. 2013;41(6):851-857.

106. Silverman I. Simple reaction time: it is not what it used to be. Am J Psychol. 2010; 123(1):39-50.

107. de Bruin EJ, van Run C, Staaks J, Meijer AM. Effects of sleep manipulation on cognitive functioning of adolescents: a systematic review. Sleep Med Rev. 2017;32:45-57.

108. Ferrara M, De Gennaro L. How much sleep do we need? Sleep Med Rev. 2001; $5(2): 155-179$.

109. Engle-Friedman M, Palencar V, Riela S. Sleep and effort in adolescent athletes. $J$ Child Health Care. 2010;14(2):131-141.
110. van Vugt H. Sleep in Context. In: Westerink J, Ouwerkerk M, Krans M, editors. Sensing Emotions: The Impact of Context on Experience Measurements. New York: Springer; 2011.

111. Horne J. Sleepiness as a need for sleep: when is enough, enough? Neurosci Biobehav Rev. 2010;34(1):108-118.

112. Horne J. Sleepfaring: A Journey through the Science of Sleep. New York: Oxford University Press; 2007.

113. Matricciani L, Blunden S, Rigney G, Williams M, Olds T. Children's sleep needs: is there sufficient evidence to recommend optimal sleep for children? Sleep. 2013; 36(4):527.

114. Watson N, Badr M, Belenky G, Bliwise D, Buxton O, Buysse D, et al. Recommended amount of sleep for a healthy adult: a joint consensus statement of the American Academy of sleep medicine and Sleep Research Society. Sleep. 2015; 38(6):843-844.

115. Your Guide to Healthy Sleep. [Internet] US Department of Health and Human Services; 2005[Available from: www.nhlbi.nih.gov/health/public/sleep/healthy_sleep.pdf].

116. National Sleep Foundation. How Much Sleep do We Really Need?; 2015[Available from: https://sleepfoundation.org/how-sleep-works/how-much-sleep-dowe-really-need].

117. Heffron T. Sleep Well, be Well: A National Health Priority; 2014[Available from: http://sleepeducation.org/news/2014/05/16/sleep-well-be-well-a-nationalhealth-priority].

118. Perry GS, Patil SP, Presley-Cantrell LR. Raising awareness of sleep as a healthy behavior. Prev Chronic Dis. 2013;10:130081. http://dx.doi.org/10.5888/pcd10.130081.

119. Morgenthaler T, Croft J, Dort L, Loeding L, Mullington J, Thomas S. Development of the National Healthy Sleep Awareness Project Sleep Health Surveillance Questions. J Clin Sleep Med. 2015;11(9):1057-1062.

120. Arora T, Broglia E, Pushpakumar D, Lodhi T, Taheri S. An investigation into the strength of the association and agreement levels between subjective and objective sleep duration in adolescents. PLoS One. 2013;8(8):e72406.

121. Girschik J, Fritschi L, Heyworth J, Waters F. Validation of self-reported sleep against actigraphy. J Epidemiol. 2012;22(5):462-468. 